\title{
Humanities-Based Assessment of Natural Scientists' Assessment of Social Science
}

\author{
Hajime Eto
}

\begin{abstract}
Confronting serious social issues, many natural scientists (including technologists) are dissatisfied with the performance of social science. Based on the natural scientific progresses, natural scientists propose the methodological innovation or revolution of social science by importing natural science methodologies. This paper identifies and formulates the dissatisfactions of natural scientists with the status quo of social science. Then this paper compares their dissatisfactions with the history of humanities around 1900. Reflecting how the 20-th century's humanities have overcome the problem of natural scientific crises, this paper advises natural scientists to remember their own history and to consider the ethos of social science.
\end{abstract}

Index Terms-Contradiction, impossibility theorem, Social Science assessment, paradox.

\section{INTRODUCTION}

Our society is suffering from a variety of serious problems like environment, resource, poverty, etc. But social science fails to provide effective prescriptions [1]. Many people are dissatisfied with this situation and criticize or discredit social science. Even social scientists criticize this situation [2]. Natural scientists including technologists are no exception (hereafter "natural scientists" includes "technologists and engineers"). Their discredit of social science leads to their discredit of government policy that is formed with the aid of social scientific knowledge. This means that natural scientists discredit all the policies including science, technology and innovation policy (shortly, science policy) of government. Without their support, science policy can not be successful [3]. Without the success of science policy, industrial innovations can not be successful [4], [5].

Based on the successful development of natural science for the recent centuries, natural scientists criticize social science and tried to find why social science failed. Particularly, their criticisms are focused on the "defects" of social science such as the unpredictability of the future or the outcomes of policies, the uncontrollability of society (economy, international and domestic conflicts, etc.), the ambiguity of social science terminologies. Natural scientists advise social science to borrow or import natural scientific methods and tools (e.g., the catastrophe theory [6], [7]) to solve social problems.

The celestial movement was already predictable even before Copernicus. In 1899, Rickert regarded the predictability as the typical success of natural science. At

Manuscript received March 10, 2016; revised April 30, 2016.

Hajime Eto is with the University of Tsukuba, Japan (e-mail: etohajime@peach.ocn.ne.jp) the almost same time, however, some philosophers and scientists (sometimes called the end of century scholars) raised a set of questions against the validities of natural science. This paper tries to learn lessons from the science history by recalling what happened about 100 years ago.

Around 1900, natural science including mathematics faced serious crises. The development of Non-Euclidian geometry in the 1800 s seemed to threaten the validity of geometry, which was regarded as the most logical system. In 1899 , Hilbert developed a new axiomatic system to logically found geometry. Humanities (knowledge or sophia with much older history and much more experiences than natural and social sciences) including formal logic, general language theories and semiotics demonstrated the indefinability, the un-decidability of the truth, validities, and other fundamental concepts of mathematics. But mathematics has remained as an essential or indispensable element of natural science or epistemology of nature and, recently, as an important tool of social science. Physics also survived these philosophical criticisms, although it had to give up the claim of its absolute trueness over the entire science.

This history seems to suggest the following conjectures or hypotheses: The "defects" of social science are the essential or inevitable natures of society itself or result from the essential natures of people in the society including natural scientists themselves. This paper will examine these conjectures or hypotheses from a methodological point of view.

The technical aspects of the transfer of methods between natural and social sciences and humanities were discussed elsewhere [8] but this paper emphasizes the differences in the views of the values or ethos of natural and social sciences and humanities by extending a foregoing discussion [9].

The data used in this paper are collected or picked up from the informal discussions and conversations between the author and several natural scientists, who had some experiences of collaborations with social or behavioral scientists on environment and other social problems. Many natural scientists are dissatisfied with social science, but their dissatisfactions have almost never been publicly expressed in explicit or formal ways for several reasons. Natural scientists are not trained or not accustomed to conceptual or philosophical discussions about problems not formulated in scientifically well-defined terms or not experimentally testable. Further, they refrain from publicly "blaming" the "poverty of social science" in explicit manners for several reasons. One reason is that many leading figures in government, industries and media have the social scientific backgrounds. Another reason is that natural scientists are afraid of the possibility that such blame 
may be harmful for the socially demanded collaborations between natural and social scientists for the problems of environment, innovation policies, etc. A third reason is that natural scientists tend to look down social scientists, many of whom are poor in mathematical knowledge and skill. In many countries including Japan, secondary school education stresses the mathematical training as the most important one and often classifies students on the criterion of mathematical performances. In this situation, it is feared that the blame of "inferior" social scientists by "superior" natural scientists may be considered as a sort of discriminating or hatred critics.

This paper formulates their fragmental complains of or informal dissatisfaction with social science into the form of critiques or assessments in Section VII.

\section{SCOPE OR DEFINITION OF SOCIAL SCIENCE IN THIS ARTICLE}

Social science is the scientia (knowledge, sophia) regarding society and its members (i.e., people) including their organizations (government, industries, etc.) mainly in the present day. The recent confusion is that many people think of economics as synonymous to social science itself (economics-centric view of social science). Some people, particularly natural scientists, consider that only economics is scientific among social science. This is natural because economy now dominates the entire society, in which almost all things are quantitatively evaluated in terms of money by using statistical or mathematical methods borrowed from physics.

Economy works well when the commodities are abundant enough to satisfy the demand fairly well. In such situations, the present economic theories explain the economic system fairly well. This condition is often satisfied in the time of peace, meanwhile the military control of industry dominates the entire economy and the entire society in the time of big wars (particularly, WWI and WWII). Tautologically, economics works well in explaining or managing the economic system when the economic system works well by balancing the supply and demand. In this favorite situation, the economic system dominates the entire society and economics dominates the entire social sciences. In different situations like wars, disasters and others, other types of social science are demanded by the military sector, the welfare sector, or others.

Social science is usually considered as the loosely connected set of several half-independent disciplines, which have been developed in history with some common grounds.

Political Science was deeply related to moral or sometimes immoral philosophies (the fundamental idea or principle of politics or ideology such as Platon's idea, or Machiavelli's il Principe or the art of wars (dell' arte della guerra) and also related to history as the treasure house of practical lessons from political successes and failures like in the Confucian's Comments on The History Book. Ethics and history are now regarded as belonging to humanities. Indeed, the founders of political science were philosophers (Platon and Aristoteles in Greece). Further, the Imperial University of Tokyo, established as the first modern university in Japan in 1877 , placed the department of political science at first in
College of Letters, although later relocated it into College of Law in 1885.

Juris Prudence (sophia or philosophy of law, or legal philosophy) was based on the supposedly universal principle of socio-ethics (Christianity, Confucianism, etc.), but now it uses rather language-analytic techniques [10]. Classically, the department of juris prudence was central in university to train government officers. As economy is nearly free from legal control today, juris prudence is no longer strongly influential over other disciplines of social science or practices.

The idea of Sociology was presented by Auguste Comte perhaps as one of the first systematic ideas for the study of the entire society [11], [12], meanwhile the economics or managerial aspects in the study of society was earlier presented by Quesnay and Smith. Simmel, a philosopher around the age of Marx, presented the Philosophy of Money but this work has usually been regarded as belonging to sociology rather than economics. In the first half of the 1900s (particularly, around the 1930s), sociology was called the Queen of social science and it covered knowledge, ideology, communication, information, media, and other areas that traditionally belonged to humanities [13]. Indeed, the Imperial University of Tokyo (The University of Tokyo after WWII), the most representative university in Japan, has placed the Department of Sociology in the College of Letters together with the Departments of Linguistics, Philosophy, and History.

Management Science or Business Study is unique in that it came partly from engineering called industrial engineering (IE) and operations research (OR). In addition to its technical methods, its philosophy [14] is very different from other social scientific disciplines, although it is now seldom remembered [15].

As was discussed above, social science has various aspects. Sometimes it is meaningless to think of the unified concept of social science, but sometimes it is meaningful to think of social science as a unique system of knowledge in distinction from natural science and humanities. This paper takes an ambiguous position to take the two positions according to the context.

This paper defines social science (SS) in a complementary or negative way; i.e.,

$$
S S=K-\{N S, T, H\}
$$

where $K$ : Knowledge or sophia, NS: Natural science; $T$ : Technology; and $H$ : Humanities.

In this definition, $S S$ is defined to include economics. It also includes the significant parts of juris prudence, political science, sociology, and management science.

\section{HUMANITIES AS THE ORIGIN OF NATURAL AND SOCIAL SCIENCES}

Every science (knowledge, sophia, scientia) can be said to have originally come from humanities, which were classically composed of philology, linguistics, classic studies, philosophy, history, cultural geography, medicine, astronomy, zoology, botany, etc. Modern natural and social sciences, at least partly, came from sophia, Modern science 
such as biology can be said to have come from classical sophia like zoologia, etc.

Later, the use of precise measurement and observation instruments (telescope, microscope, etc.) and the idea of experimentalism (the test was regarded as doubting the god and often religiously prohibited in the old days) have separated natural science from the speculation-based or reasoning-based sophia. Further, the decline of the idea of religion-based ethics (ethos) has separated juris prudence and political science from legal and political philosophy and promoted their development to realistic socio-techniques or maneuvers without ethical foundation (value-free).

Economics is much younger than juris prudence and political science. Except for oikonomia that meant the household management of big family in Ancient Greece, modern "scientific" economics was established much later by Smith, Quesnay, etc. in the 1700s.

Management science (MS) is young and has the technological origins. It developed itself from operational (or operations) research (OR) organized during WWII under the leadership of natural scientists, technologists and science philosophers.

History and geography are as old as sophia itself and are often regarded as belonging to humanities. Starting with the philological or exgenetic studies of old documents, history has analyzed social (e.g., political) problems up to the present to provide decision makers with historical lessons and deeply influenced the development of social science. Geography has provided social leaders with natural, cultural and other information and helped their decision-making. In these aspects, the knowledge of humanities was extremely important to train social leaders.

Having forgot the historical fact that the origin of social science was deeply related with humanities, their intellectual exchange is limited today. One reason may be that the contemporary society is mainly based on economy, which has historically been almost ignored in humanities. In fact, oikonomia was not regarded as important in Greece.

\section{ECONOMICS-CENTRIC SOCIAL SCIENCES}

Among what is now called social science, economics is the most dominant today. Sociology once covered even the areas of knowledge, myth and ideology around the interwar period and was called the Queen of social science. Having forgot the history of the dynamic era in the 1930s, economics now takes the position of the Queen of social science, because the economic powers influence elections, politics and media. Except for economics, the territories of social science have still been overlapped with humanities.

\section{OBJCTS AND OBJECTIVES OF NATURAL AND SOCIAL SCIENCES}

Social science is different from natural science in many respects. Everybody knows that the object of natural science is the nature while that of social science is the society. Everybody knows the difference between the nature and the society. The problem is how the difference in objects makes the differences in their objectives, values and methods.
The object of medical science is the human being. This decisively characterizes medical science in distinction from other natural science. Even with the same object, further, fundamental medical science and clinical medical science are different in method and value.

The major method of natural science is the experiment, which usually uses high-tech instruments and is often done within well-designed artificial laboratories. Fundamental medical science also uses experimental methods. Meanwhile, clinical medical science "theoretically" could but ethically does not make experiments as the major method, because the objective of clinical medical science is to value and respect humans and therefore the object (humans) is inviolable. In another aspect, social scientists (particularly, sociologists) sometimes experiment on human group behaviors but never on the human society itself, because social scientists are included in human society and the latter forces the former to have the objective to respect the human society and not to control or conquer it.

A similar argument may hold for the difference between fundamental earth science and seismology. One of the objectives of fundamental earth science is to observe and to measure the phenomena in precise ways and to try to build well-founded theories while refraining from providing "rough and ready" or inexact information of earthquake risks. Meanwhile one of the major objectives of seismology is to warn the public of possible dangers even long before their indications are scientifically observed. Further, seismologists tend to refrain from experiments (e.g., man-made earthquakes) for the reason to avoid real risks. In these aspects, seismology tends to place the weight on the observations rather than the experiments.

A similar argument may hold for volcanology. The public requests volcanologists to warn the risks even in rough ways rather than to provide a scientifically exact theory. In fact, Japanese volcanologists changed the policy after a disaster a few years ago and now "sacrifice" the scientific exactness rather than sacrificing human lives for the scientific exactness.

As the object of social science is the contemporary society that is already known to people, social science generally can not discover novel fact. This makes social science different from classics-centric humanities. The most fundamental areas of humanities are history, cultural geography, archaeology, and classics, where new discoveries are respected as the most valuable contributions to the academic communities. If the "true" birthday of Socrates is identified or confirmed, or if a missing page of a Napoleon's letter is discovered, these discoveries are the most valuable contributions to the study of history, although many people misunderstand history for the exiting stories of historic battles in popular books or TV dramas, or the histo-philosophical explanations or interpretation of historic events, etc. However, for many years, it was a main focus of scholastic research of history and classics whether the war of Troy (Troia) was real or fictitious. The archaeological discovery of the ruin of Troy by Heinrich Schliemann has been highly evaluated in the scholastic community.

It may be surprising to many people that the fundamental part of "obsolete" humanities shares the discovery-seeking characteristics and the discovery-estimating values with 
modern natural science. This is because the objects of humanities are the old era, the old societies or the old works, or the objects of cultural geography or anthropology are the societies located in distant and unfamiliar areas like the Amazon area.

Some natural science can not directly experiment on the objects in or on which the observers live; such as the entire earth itself or the entire universe itself. As nobody can directly see him(her)self without mirror, no natural scientist can directly experiment on the world containing scientists themselves as its part.

Most of natural scientific achievements are done within artificial laboratories or indirectly by way of artificial apparatuses, which play the role of mirror to make the invisible objects visible as images. From a philosophical or epistemological point of view, many of the "modern" achievements of natural science are artificial rather than natural possibly except for some botanical or zoological discoveries in the field by farmers, who observe plants or insects with the own naked eyes and fingers. In the 1200s, Roger Bacon stressed the importance of observation (he invented a magnifying glass or a sort of microscope) and of experiment. Seemingly contradictorily or consistently, he criticized the human recognition of the real world as the mirror image on the wall in the dark cave.

When economy was small in scale and played only a minor part in the society, its action little influenced the entire society. Around 1200, Honen and Shinran, a Japanese Buddhist and his disciple, regarded the human acts as negligibly minor ones on the Buddha's hand and as giving no significant effect on the entire society and therefore regarded the human acts as pardonable. Later, Smith presented the similar statement as the economic version. Ignoring Smith, however, economic ethics based on the homo-economics view of humans does not prevent economy from its large-scale activities. Smith's classic economics and modern economics have the same objects. As the society has now grown to a large system, however, the objectives and values of Smith and modern economics are required to change.

\section{LEGACY OF HUMANITIES IN ASSESSING NATURAL SCIENCE}

In the late 1800s and the early 1900s, the development of physics and mathematics ironically raised serious questions concerning their validities. In particular, the arguments were concentrated on the validities of the theories of statistical physics, relativity theory, quantum physics, geometry, and others.

Science philosophers, science historians, logicians, and philosophical scientists joined the arguments concerning the fundamental problems of natural science and mathematics. The results were the construction of more logical systems and re-interpretation of mathematics and physics. But this effort ironically generated a paradox: Russell demonstrated that the self-negation results in a paradox, which is necessary or inevitable in mathematics.

Besides this paradox, many "negative" or the self-negation results were generated: The incompleteness of mathematics and the indefinability of the validity or the truth criteria were logically proved [16]. That is, the most important concepts in mathematics were logically proved to be poorly founded. This is a very valuable legacy of philosophy concerning natural science including mathematics. This legacy is systematized and is called meta-science or meta-mathematics. The fundamental idea of meta-science will be extended to the meta-scientific discussions on social science in Section VIII.

\section{ASSESSMENT OF SOCIAL SCIENCE By NATURAL SCIENTISTS}

Natural scientists are dissatisfied with social science in several respects, and criticize or assess it as follows.

Assessment 1. Unpredictability: Social science fails to predict social events and phenomena.

Here, the contrast between the predictability of natural science and the non-predictability of cultural science (cultural geography or anthropology) by the Neo-Kantian philosophers like Rickert around 1900 is straightly extended to the contrast between natural science and social science.

For the astronomic system with two bodies (e.g., Sun and Earth), the fairly precise prediction has been successful even before Copernicus. The prediction of the behavior of multi-body system is difficult even today. But statistical physics gives the fairly exact prediction of behavior of infinitely many particles systems (e.g., the atmospheric system). In fact, the weather change has been forecasted with some probability of success. Meanwhile, social science fails to predict the international or domestic conflicts such as world wars, economic depressions, etc. Exceptionally, Lenin presented the theory of the imperialism and successfully predicted a global war (WWI) and a revolution. After WWI and Russian Revolution, a young Russian economist predicted a great economic depression in the late 1920s. Indeed, Great Depression came in 1929. But these predictions were recognized in the social scientific communities only after the war, the revolution and the depression really took place, because the majority of social scientists themselves did not trust the validity of the Marx-Leninism.

Assessment 2. Uncontrollability: Social science fails to control social events or social phenomena such as wars, depressions, crimes, etc.

There may be no need to explain what this assessment means. Social scientists failed to provide appropriate means to prevent World War or Great Depression.

Assessment 3. Indefinability or ambiguity of terminologies: The terminologies in social science are not uniformly defined. That is, different social scientists use different terminologies for the seemingly same or similar phenomena or concepts.

This is contrasting to natural science, where most of essential concepts are defined by international societies, although there are some exceptions even in the symbol of elements: The symbol of the iodine (Jod) is ambiguously I or J. The definition of planet is so ambiguous that the Pluto is sometimes counted as a planet but in other times not a planet. The definition of metal is so ambiguous that $\mathrm{Na}$ (Natrium or Sodium) is sometimes counted for a kind of metal but in other times not a metal. Despite these examples, 
however, the terminologies of natural science are much less ambiguous than those of social science.

Assessment 4. Narrow-minded exclusivism-like endogeneity in methods: Social science declines or fails to learn or import scientific methods developed and proposed by natural scientists.

In the late 1900s, a variety of methods were presented by natural scientists mainly for social sciences: Besides the aforementioned catastrophe theory, proposed were the bifurcation model [17], the complexity theory [18], quantum chemistry model [19], self-organization, self-assembly, phase transition or phase shift model [20], etc. But very few of them have been really implemented in social science.

\section{HumANITIES-BASED ASSESSMENT}

Using the historically accumulated legacies and the wisdom of humanities based on the thousands years experiences, this section assesses the above-stated assessments of social science by natural scientists. As natural science has much shorter history and has accumulated much less experiences than humanities, it may be anticipated or conjectured that the natural scientists' assessment of social science is not necessarily based on the profound view. At first, it may be noted that natural scientists unknowingly make the self-contradictorily criticism against natural science itself as a result from ignoring the experiences and the legacies of humanities regarding the validities of natural scientific truth. Let us examine phenomena and conditions that reveal the "limits" of natural science and lead to the self-contradictory criticisms against natural science itself.

\section{Assessment 1:Unpredictability}

It should be remarked that natural science often fails to predict some phenomena under some conditions like the conditions of field outside laboratories. History shows that natural science almost always failed to predict big earthquakes with the requested precisions. A decade ago, the Japanese seismology community officially declared to abandon the effort to predict earthquakes for the reason that such an effort is outside science or non-scientific. The reason is clear. The object (the earth) is too big to observe in sufficiently precise ways. Here, "too big" means that it is beyond the power or the capability of natural scientific observations. Natural science could "theoretically" claim to move the earth by lever. But no natural scientist can claim to provide such lever because the object (the earth) is too big (too heavy). The objective (to prevent the disaster) is too severe. As for diseases (influenza, etc.), the objects (the number or the population of viruses or patients) are too numerous and the objective (to exterminate the viruses or the patients) is too severe.

Natural scientists may defend themselves against this criticism in the following way: Natural science always predicts such disasters and diseases with some probabilities. Yes, it is true in some sense. In this sense, however, social science has also predicted wars, economic depressions, etc. with some probabilities. This difference comes from the difference in system scale or system size. "Social disasters" (war, economic depression, etc.) kill more people, destroy or damage more properties, etc. than natural disasters.
Since the mid 1900s, natural scientists have tried to predict or forecast technological advances [21]. Despite the efforts, however, its exactness is not high enough. Rather, the social scientific approaches to technological advances are fairly exact [22] or the socio-psychological interpretations of the forecasting actions might be more meaningful than the prediction itself [23].

The social prediction tends to raises some serious problems. If social behaviors or acts are perfectly predictable, then the privacy is disclosed. Demon (Daemon, Daimon) was originally no bad devil but only the intermediate spirit between gods and humans. It merely predicted the human acts or read the human minds. Then the Greek people began to regard Demon as the devil. If police tries to predict the citizen's acts, this would raise the citizen's resistance.

In social (military, political, economic, etc.) conflicts or competitions or in private matters, the discussions about the perfect predictabilities lead to the logical contradiction as was shown in a Chinese classic story of wisdom about the contradiction between the perfect spear and the perfect shield: What happens if the perfect spear attacks the perfect shield? As the spear is perfect, it breaks any shield with no exception; meanwhile the perfect shield defends any spear with no exception. What happens if the both sides perfectly predict each other in war, politics or business? The mutually perfect prediction leads to a contradiction or is logically impossible in social competitions or conflicts. The perfect prediction is possible (probably only) when one side has more or better abilities than the other side like in the relationship between adults and babies or between masters and dogs. As people say, babies tell no lie and dogs never betray the masters. For simple phenomena of nature, humans (farmers, hunters, fishermen, etc.) are intelligent enough to predict daily phenomena or events (rain, the behaviors of animals or fishes, etc.). For mega-social phenomena like disasters, the public requires social scientists to predict mega-events or complicated matters like wars or economic depression with the high precisions. Meanwhile, few people require natural science to predict mega events of the nature (mega-quake, etc.). An exception was seen for the earthquake in Italy in 2009, Italian people and the court required natural scientists to predict the earthquake [24]-[26]

\section{Assessment 2: Controllability}

The predictability tends to lead itself to the controllability [27]. Everybody including natural scientist does not want to be controlled. Social unpredictability leads to social uncontrollability, which assures people of peaceful mind and happy lives. Another example of unpredictable science is medical science, which does not tell the exact date of death. This encourages people to live.

It should be noted that the predictability is not necessarily desirable to people including natural scientists. If social behaviors or acts are perfectly predictable, then the all privacy is disclosed. If technology forecasting perfectly predict the future development of science and technology, governments can control scientific activities, which scientists may not want. The Laissez Faire system of science and technology is lost. First of all, no scientist may want to cooperate such powerful technology forecast 
activities.

Another fundamental question of people against natural science is why natural science fails to control earthquakes, volcanic eruptions, climate changes, etc. People do not ask these questions because everybody knows that natural science can just observe but not control the nature, as Greek philosophers characterized science as theoria that meant just the observation or speculation. Even science-based technology remains and probably will remain theoria for large-scale natural disasters like earthquakes.

Assessment 3. Indefinability or Ambiguity of Terminologies.

First of all, the concepts of truth or validity are not logically decidable [28]. This means that the truth is indefinable or that meaning of truth is logically ambiguous. This fact seems to result from the essential nature of human recognition.

The second problem is who define terminologies. Social scientific studies may be characterized by the citizen's participation. Not only professional social scientists but also bureaucrats, journalists, businessmen or women, election voters join or influence social scientific studies. A variety of people view the same society from different angles. This generates a variety in social science and the terminologies. This is contrasting to high-energy physics, where only "selected" scientists accessible to particular apparatus can participate in defining their "dialects" as the standard terminologies.

In some areas of natural science called small science in contrast to big science like high-energy physics [29], however, the situation is similar to the situation of social science. In small science like botany, zoology, agriculture, herbal medicine, etc., many "amateurs" play important roles and their "dialects and broken grammars" decisively influence the terminologies of small science (the amateurs suffrage system).

Many sociologists and writers positively evaluate the citizen's participation in social fields like elections. It is often desired that political, economic, educational, welfare and other policies are influenced or even controlled by the voice of non-professional citizens, although professional leaders and bureaucrats try to oppress or "correct" amateur opinions. It may be a central problem of science policies which system is more desirable.

Assessment 4. Narrow-minded Exclusivism-Like Endogeneity of Methods

Social science fails to learn or import scientific methods developed by natural scientists.

In fact, natural scientists presented many scientific methods partly or even mainly to social science in the recent decades. But social scientific communities have been conservative or reluctant to accept and use these methods.

The reasons of this reluctance are multiple, but one reason is that the fundamental ideas underlying the natural science-origin methods are exogenous, inadequate or alienate to the fundamental ideas of social science and are unusable to social scientists, as the logically strict mathematical systems proposed by logicians and mathematical philosophers are unfamiliar, alienate or unacceptable to the majority of mathematicians, most of whom were educated in the college of natural science with almost no close friend with the social science or humanities backgrounds.

The significant parts of social science originally came from history, which is one of the oldest knowledge (sophia). History has long provided political or intellectual leaders with ethical lessons besides practical or tactical lessons. Based positively on historical documents (exegetics) by scholiasts, history has been the accumulated storage of lessons and has told people ethical lessons. History has long treated important persons not only as strong or talented persons but also as respectable leaders. Historians have long regarded (or at least tried to regard) important leaders as possessing the elevated mind and the talent of morally influential leadership. At first, Hegel regarded Napoleon as the embodied Spirit or Reason of World History or as developing history by realizing the idea, and he kept this view of history even after he began to devalue Napoleon.

Even today, many people (want or wish to) consider that the historical development processes are the realization processes of desired ideas (economic prosperity, democracy, the emancipation of slaves, woman suffrage, etc.), even if constrained or partly motivated by material desires. As part of humanities, history is the sophia that tends to regard the human acts as the humane (rather than material or physical) acts. Except for clinical medicine, natural science even including biology treats material or physical objects including animals, and its objective is to control them often by destroying or killing them. Even modern economists are reluctant to killing animals, even if they are committing themselves with reducing or destroying the biodiversity.

Social scientists (possibly except for modern economists with the view of homo economics) feel that the methods presented by natural science are suitable to the physical, material or monetary processes but are not necessarily relevant to the traditional ethos of history-origin or humanity-origin social science.

\section{DISCUSSIONS AND CONCLUSION}

The above-stated historical legacy of humanities may show that the "defects" of social science are essential or inevitable results of society itself or the essential natures of people in the society including natural scientists themselves. As a part of society composed of people including natural scientists themselves, social science can not conquer the society composed of "ill-natured" people. As Chinese classics tell, it is a contradiction that social science can conquer the society and perfectly control people including natural and social scientists themselves. This is particularly so under the election-based democratic system, where the social control is constrained or controlled by the majority people in the society.

Social science has the essential limit not to control or exterminate "ill-natured" people as astrophysics can not control the "ill-natured" solar system including the "ill-natured" earth, because social scientists are merely their elements.

Dissatisfied with the poor performances of social science in solving a variety of social issues, natural scientists severely criticize and assess social science in several aspects. This paper showed that the severe assessments of social science by natural scientists are largely based on their 
misunderstanding of the fundamental characteristics of social science, which are deeply constrained by the essentially uncontrollable properties of society itself. This paper learns the lessons or the achievements presented by humanities about 100 years ago regarding the limit of natural science like the impossibility theorem. More specifically, humanities (knowledge older than science or used to include science as its element) including formal logic and semiotics demonstrated the indefinability of terminology, undecidability of truth or validities, etc. (shortly, the logical limit or impossibility of mathematics or physics), although these are the inevitable limits but essential elements of natural science.

This history regarding the essential "limits" of natural science indicates that the "defects" of social science are from the essential or inevitable properties of society itself or the essential characters of people within the society including natural scientists themselves. As a part of society composed of people including natural scientists themselves, social science can not conquer the society of "ill nature". It is a contradiction that social science can conquer the society and perfectly control people including natural scientists. Social science has the essential limit not to control people.

This paper showed that social science can not go beyond the social limit of humans just as natural science can not go beyond the limits imposed by the nature itself.

The mutual understanding and respect between natural and social sciences and humanities are requested. This is expected to help their collaborations to (even if only partly) solve the social issues like health, environment, resources, energy, education, etc.

Some important problems remain unanalyzed here. Social science is sometimes required to radically revise or revolutionize itself. This was once proposed by Popper as social engineering or as an extension of natural scientific revolution (particularly the success of quantum physics) around the 1930s [30].

In the $1960 \mathrm{~s}$ and $1970 \mathrm{~s}$, natural scientists presented another idea called social technology. This was to base science, technology and innovation policy on the prediction (forecasting) of scientific or technological development [31].

In the $1950 \mathrm{~s}$ and $60 \mathrm{~s}$, the idea of cybernetics was introduced into social science [e.g., 32].

These topics remain unanalyzed in this paper and are to be discussed elsewhere.

\section{REFERENCES}

[1] J. Falck-Zependa, J. Wesselei, and S. J. Smyth, "The current status of the debate on socio-economic regulatory assessments; Positions and policies in Canada, the USA, the EU and developing countries," World Review of Science, Technology and Sustainable Development, vol. 10, no. 4, pp.203-227, 2013.

[2] A. Sen and J. Dreze, Hunger and Public Actions, Oxford: Oxford University Press, 1989.

[3] H. Eto, "Obstacles to the acceptance of technology foresight for decision makers," International Journal of Foresight and Innovation Policies, vol. 1, no. 3-4, pp. 232-242, 2004.

[4] G. Mensch, Das Technologische Patt (Stalemate in Technology), Frankfurt: Umschau Verlag, 1975, Cambridge, MA: Ballinger, 1978.

[5] G. Mensch, "A new push of basic innovations?" Research Policy, vol. 7, pp. 108-122, 1978.

[6] V. I. Arnold, Catastrophe Theory, 2 nd ed. Berlin: Springer, 1986

[7] R. Gilmore, Catastrophe Theory for Scientists and Engineers, New York: John Wiley, 1981.

[8] H. Eto and S. Yamamoto, "Methodology transfers between social sciences and humanities in relation to natural sciences, technology and government policy," in Theoretical and Methodological
Approaches to Social Sciences and Knowledge Management, A. Lopéz-Varela, Ed. Rijeka, Croatia: Intech, 2012, ch. 2, pp. 33-52.

[9] H. Eto, "Humanities' assessment of natural scientists' assessment of social science," presented at the IEDRC Conference, Tokyo, December 30-31, 2015.

[10] H. L. A. Hart, The Concept of Law, Oxford: Oxford University Press, 1961.

[11] A. Comte, "Course de philosophie positive," pp. 1830-1842.

[12] A. Comte, Systéme de Politique Positive, pp.1851-1854.

[13] K. Mannheim, Ideologie und Utopie (Ideology and Utopia), 1929.

[14] C. W. Churchman, R. L. Ackoff, and E. L. Arnoff, Introduction to Operations Research, New York: John Wiley, 1957.

[15] H. Eto, "Authorship and citation patterns in management science in comparison with operational research," Scientometrics, vol. 53, pp. 337-340, 2002.

[16] S. C. Kleene, Introduction to Metamathematics, Amsterdam: North-Holland, 1952.

[17] J. Guckenheimer and P. Holmes, Nonlinear Oscillations, Dynamical Systems, and Btfurcations of Vector Fields, Berlin: Springer, 1983.

[18] D. Byrne and G. Callaghan, Complexity Theory and the Social Sciences: The State of the Art, London: Routledge, 2013.

[19] H. Eto, "A parallelism between natural and social interfaces," Revue Internationale de Systémique, vol. 12, no. 2, pp. 161-176, 1998.

[20] G. Nicolis, and I. Prigogine, Self-organization in Nonequilibrium System, From Dissipative Structures to Order through Fluctuations, New York: John Wily, 1977.

[21] H. A. Linstone, "Complexity science: Implications for forecasting," Technological Forecasting and Social Change, vol. 62, pp. 79-90, 1999.

[22] J. D. Farmer and F. Lafond, "How predictable is technological progress," Research Policy, vol. 45, no. 3, pp. 47-665, 2016.

[23] H. Eto, "The suitability of technology forecasting/foresight methods for decision systems and strategy, A Japanese view," Technological Forecasting and Social Change, vol. 70, no.3, pp. 231-249, 2003

[24] R. M. Allen, "Transforming earthquake detection?" Science, vol. 335, issue 6066, pp. 297-298, 2012.

[25] E. Boschi, "L'Aquila's aftershocks shake scientists," Science, vol. 341, pp.1451-1451, 2013.

[26] E. Cartlidge, "Quake experts to be tried for manslaughter," Science, vol. 332, issue 6034, pp. 1135-1136, 2011.

[27] G. M. Dobrov and L. P. Smirnov. "Forecasting as a means for scientific and technological policy control," Technological Forecasting and Social Change, vol. 4, pp. 5-18, 1972.

[28] A. Tartski. Undecidable Theories, Warsaw: Polish Academy of Science 1953

[29] D. de Solla Price, Little Science and Big Science, New York: Columbia University Press, 1963.

[30] P. Catton and G. Macdonald, Karl Popper: Critical Appraisals. London: Routledge, 2004

[31] H. Grupp, and H.A. Linstone, "National technology foresight activities around the world. resurrection and new paradigms," Technological Forecasting and Social Change, vol. 60, pp. 85-94, 1999.

[32] K.W. Deutsch, The Nerves of Government. Models of Political Communication and Control, New York: The Free Press, 1966.

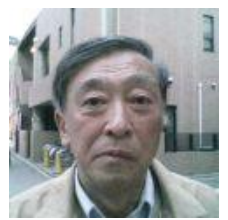

Hajime Eto was born in Tokyo, Japan in 1935. He studied science philosophy at the University of Tokyo and operations research at the University of California, Berkely. After teaching several subjects related to policy science, social technology and operations research at the University of Tsukuba Japan, he is now a professor emeritus, the University

of Tsukuba, Japan.

He has published about 90 articles mainly in international journals and a couple of books on science and technology pol.

His publications include the following books. H. Eto, $R \& D$ Management Systems in Japanese Industries, Amsterdam: North Holand,1984.

H. Eto, $R \& D$ Strategies in Japan - The National, Regional and Corporate Approach, Amsterdam: Elsevier, 1993.

He serves many scientific journals as the editorial board member 